International Journal of Engineering \& Technology, $7(2.24)(2018) 376-380$
International Journal of Engineering \& Technology
WPC
Website: www.sciencepubco.com/index.php/IJET
Research paper

\title{
Automatic Material Segregation Using PLC
}

\author{
P.Elamurugan $^{1 *}$, K.VinothBresnav ${ }^{2}$, D.Abirami ${ }^{3}$, K.G.Suhirdham ${ }^{4}$ \\ ${ }^{1,2}$ Assistant Professor, Chettinad College of Engineering \&Technology, Karur \\ ${ }^{3} U G$ Student, Government College of Technology, Coimbatore \\ ${ }^{4}$ Lecturer, MIT Polytechnic, Musiri \\ *Corresponding Author Email: elamurugan.p@gmail.com ${ }^{1}$
}

\begin{abstract}
At the present timeunusedghettoizationindications a vivaciousstarring protagonist in discardedsupervision system. The inappropriateapartheid of variegatedsurplus that split ends up in landfills sort out not fadingas it ought to be. This red-top grants knowledge of ghettoizing the substantial inevitably concluded the assistance of programmable logic controller (PLC). This treasure troveobliging to moderate the manual maneuver in the progression of reconditioning the alienatedquantifiable such in place ofpewter, cut-glass, malleable and supplementary devises crumpled consuming the air-filled piston. The dissimilar capacitive, proximity sensors etc. devours engaged in the process. The reprocessed product which partakes per received mutable byproduct. The sensible stirring on a conveyer belt intuited by the relevant sensors segregated into poles apartcontainers using a gearing contrivance. The entire component partakes organized by a programmable logic controller (PLC) staysencodedthroughPLC language by means of ladder logic.
\end{abstract}

Keywords: PLC,Proximity Sensors, Inductive, Photoelectric, Capacitive.

\section{Introduction}

In todays it is obligatory to reprocess the discarded that is accessible in the dump yard this are been physically detached so to moderate the slip it is been industrialized to computerization. .Figure 1 depicts the block diagram that intends seclusion of hefty volume of firm surplussubstantial in voluminous progression. In this venture, assets are alienated for circumstance in pointas metal, plastic and glass subsequently they endure and rehabilitated for ancillary practice. This stance integrated and organized by PLC. In numerical form operative automated gadget habits a programmable memory aimed at the core storage of instructions by instigating convinced practicalitiesby genre oflucidity sequencing, scheduling, calculating, and reckoning to control, clinched numeral or referent input/output segments, countless categories of equipment or progressions. The cardinal computer which is cast-off to realize the utilities of a programmable controller is painstaking to be within this scope. Drum and further akin perfunctory sequencing controllers are excluded.

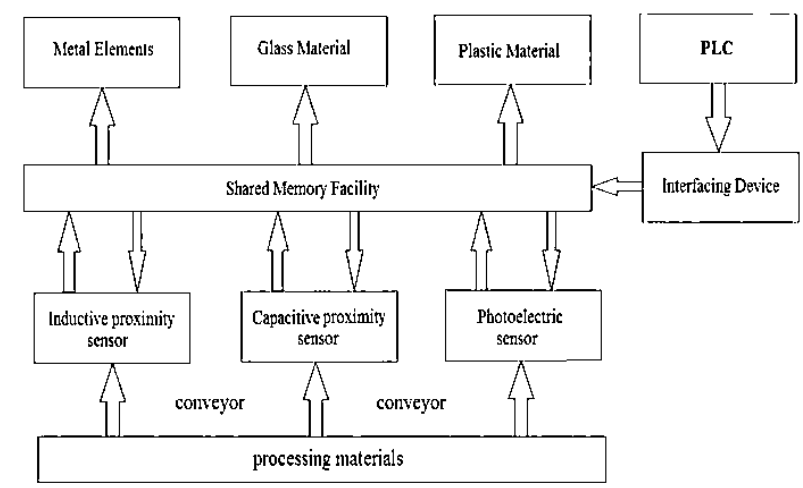

Fig. 1: Block Diagram

\section{Subject Index}

\section{PLC:}

PLC is a stratagem standardizes the yield maneuvers reliant on the industrialized program and the contributiondevices. Towardsacquireextreme efficiency from machine and govern them through human logic. En route formoderatecomposite circuitry of entire system and to eradicate the astonishingoverheadsallied with inflexible, relay-controlled schemes "LOFT LADDER LOGIC" user interface design language cast-off to epitomize electrical sequences of tasks. PLC was premeditated to affordtractability in control based programming. Figure 2 Shows a PLC Hardware Module.

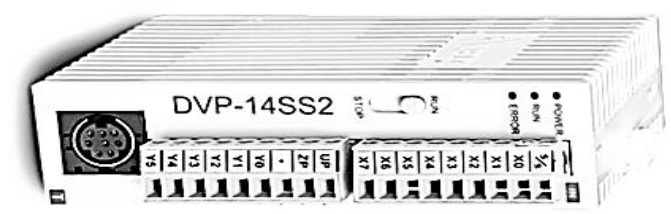

Fig. 2: PLC Hardware Module

\section{Inductive Proximity Sensors:}

Inductive Proximity instrumentrelics a set of non-contact stipulated proximity sensor charity to perceive the locus of pewtersubstances. The intuiting choice of an inductive governing contrivance reliant on run through of detected metal existence. Ferrous metals dwelling of iron and steel permit aimed atallencompassing pick up range despite the circumstance that nonferrous metals, in abode of aluminum and coppercompetent to condense the recognizing range up to 60 percent. Subsequently the yield of an inductive sensor ingests two promising states; an 
inductive sensor proceeding occasion referred as an inductive proximity switch. By dint of Faraday's law, Inductive sensor mechanismgiven away in figure 3 contrivesconstructed. Progressive disparities of the entrancing flux terminated and prepared with $\mathrm{N}$ turns path tenacity to tempt a voltage traces:

$$
e=-N \frac{d \phi}{d t}
$$

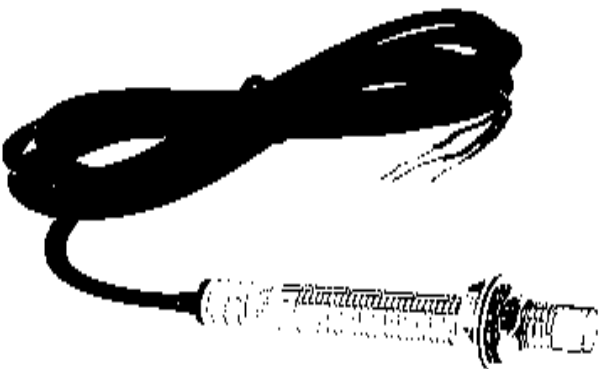

Fig. 3: Inductive Proximity Sensors

\section{Photoelectric Sensor:}

Emitter and receiver together accommodated and routine the light replicatedunswervingly off the entity for revealing. In the routine of these photocells, it is imperative to bear in mind the color and the categoryapparent of the objective. By means ofimpervious surfaces, the intuitingvastness is pretentious by the pigment of the object. Figure 4 shows the photoelectric sensor.

Daintydyesrelate to the determinedremoteness and vice versa. In the case of glistening objects, the upshot of the surface is furthermomentous than the color. The intuiting distance in the methodologicalfacts is allied to understated white tabloid.

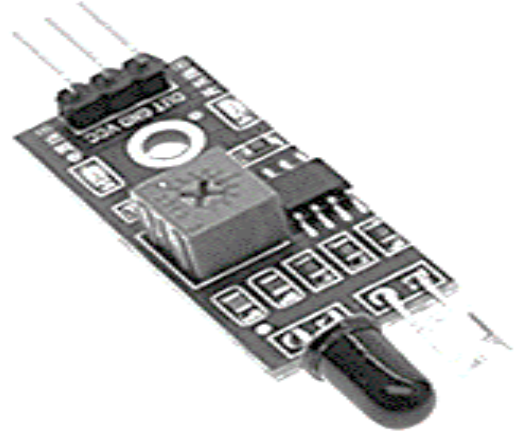

Fig. 4: Photo Electric Sensor

\section{Capacitive Proximity sensor:}

Capacitive proximity sensors displayed in Figure 5 associated towards inductive Proximity sensors. The foremost transformation amongst the dualistic sets exists that capacitive proximity sensors yield an electrostatic field asstandbyforan electromagnetic field. Capacitive proximity switchesself-controlintellect metal as well as nonmetallic materials such abode of paper, cut-glass, fluids, and fabric. The detectingsuperficial of a capacitive sensor is moldedby dint oftwofold concentrically premeditated metal electrodes of an unwound capacitor. Despite the fact an entityslants the sensing apparent it fractious the vergeelectrostatic field of the electrodes and vicissitudes the capacitance in an oscillator circuit. As anupshot, the oscillator instigates oscillating. The elicit path declaims the oscillator's amplitude extents the output state of the sensor precise level. As the aimpassages away from the sensor the oscillator's amplitude diminutions, switching the sensor output rear to its unique state.

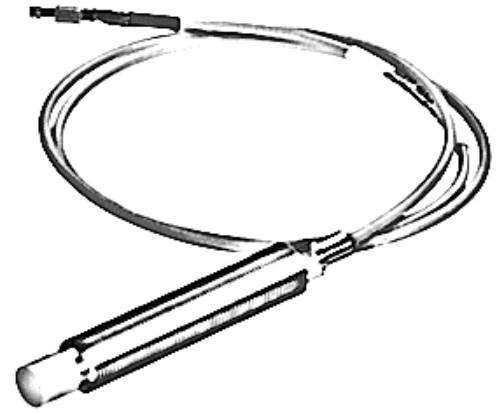

Figure 5. Capacitive Proximity Senso

\section{Software Description}

As soon as the practice is captivating place, conveyor is instigate to swap. The entityretained in conveyor is passagewaysbeside the conveyor recognized by the relevant sensor. The entity is retained in metallic element recognized by inductive proximity sensor(metal sensor) excessivelycontributes the insinuation to PLC supervisor, the outputregulatorsorts the DC motor drive to revolve the door mechanism to detached the metallic constituent to plummet in relevant bin 1.Else if it is a glass portion ,the capacitive proximity sensor (glass sensor) intellect the piece and offers the gesture to PLC organizer ,the productivity of switchvarieties the DC motor drive to revolve the door mechanism to discrete the metallic component to descent in respective bin 2.If notit is a plastic componentidentified by photoelectric sensor (Plastic sensor) springs the gesture to PLC controller ,the output of switchsorts the DC motor drive to alternate the door mechanism to dispersed the metallic element to descent in relevant bin 3.The constituentsupplementarydeterminationplummet in bin 4. Figure 6 portrays the programing flowchart for PLC.

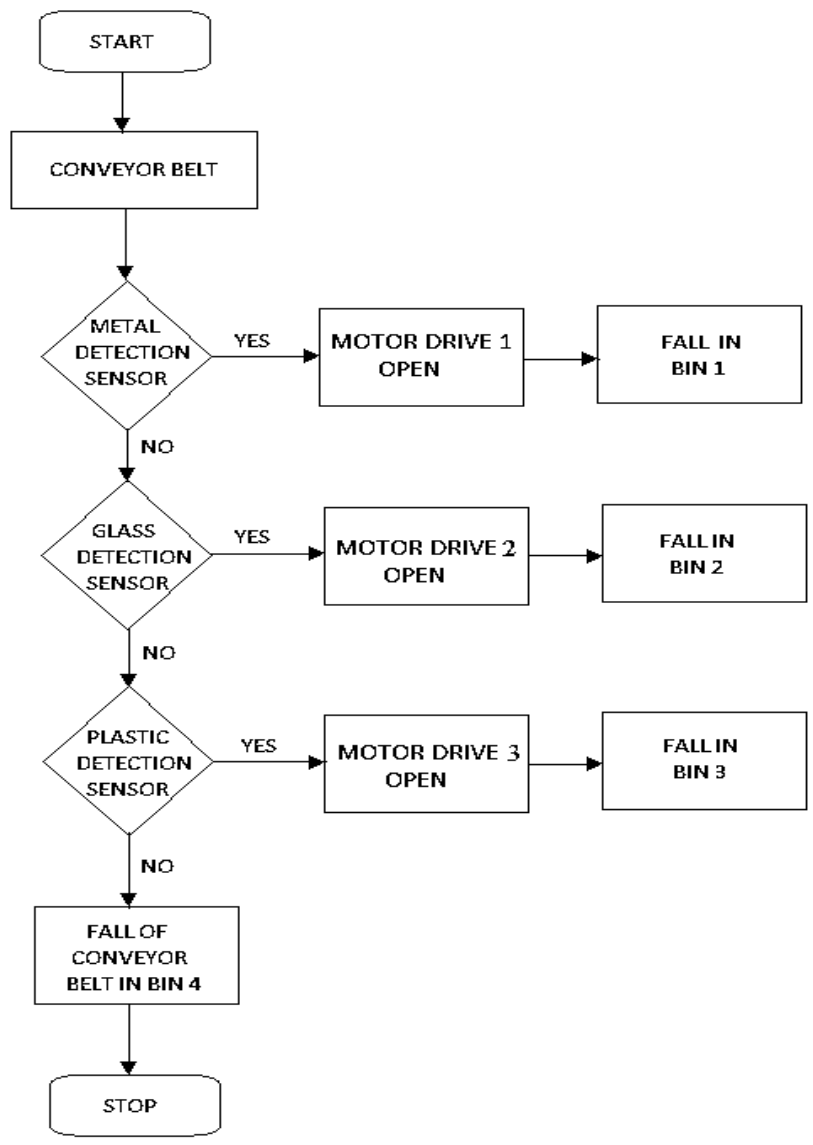

Fig.6: Flowchart 
Delta WPL Soft V2.30 or V.2.33 platform is exhausting for proposal the ladder logic for PLC. In general, separate compendium obligatory for unnumbered kind of PLCs. Still the conviction of ladder practicality is identical for all PLC package. The foremost modification of PLCarray is addressing of constituent like commonly open, commonly shut etc. WPL Soft database editor of Delta DVP series PLC for WINDOWS workstations. In totaling to universal PLC programming and WINDOWS piece of writing functions (e.g. Cut, paste, copy, multi-window show, etc.), WPL Soft conjointly affords varied comment piece of writing furthermore as alternative distinct functions (e.g. register piece of inscription and settings, foldercall up and redeemable, interactions observance and locale,etc.)

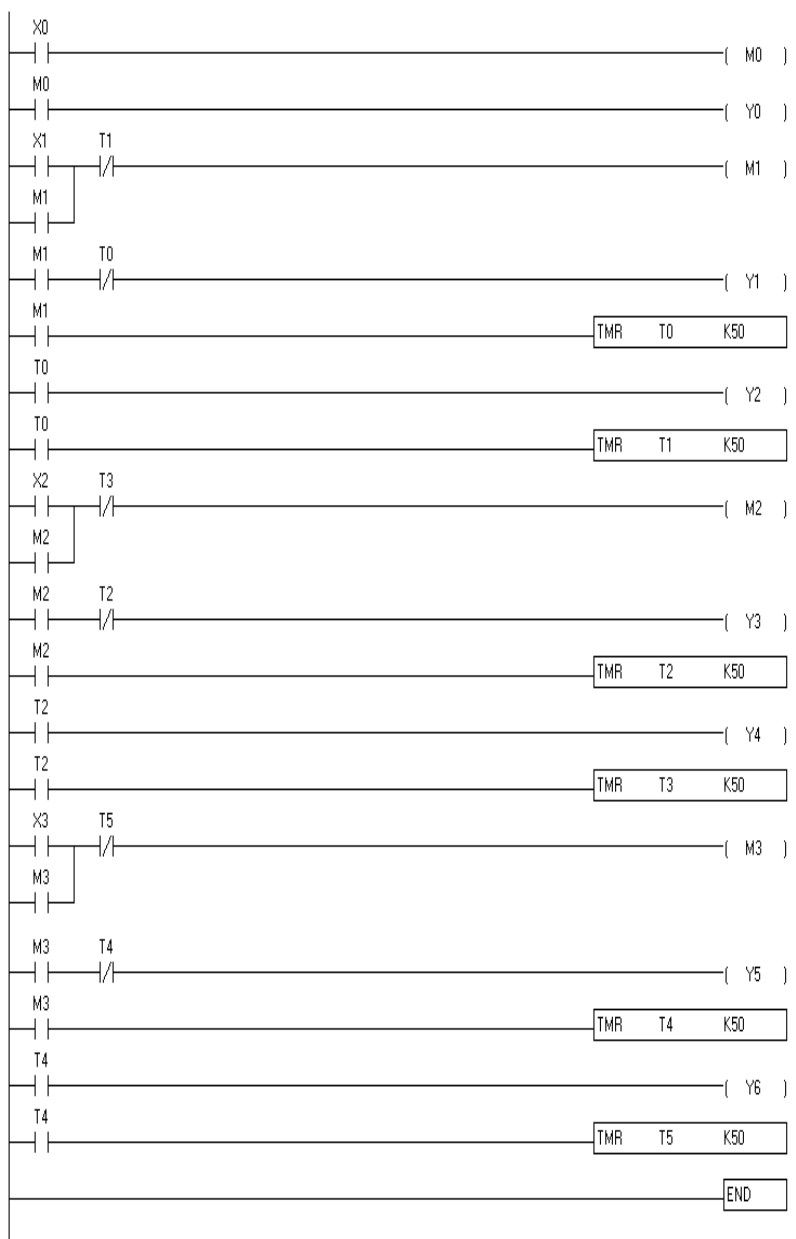

Fig.7: Ladder Logic Program

\section{Simulation Output}

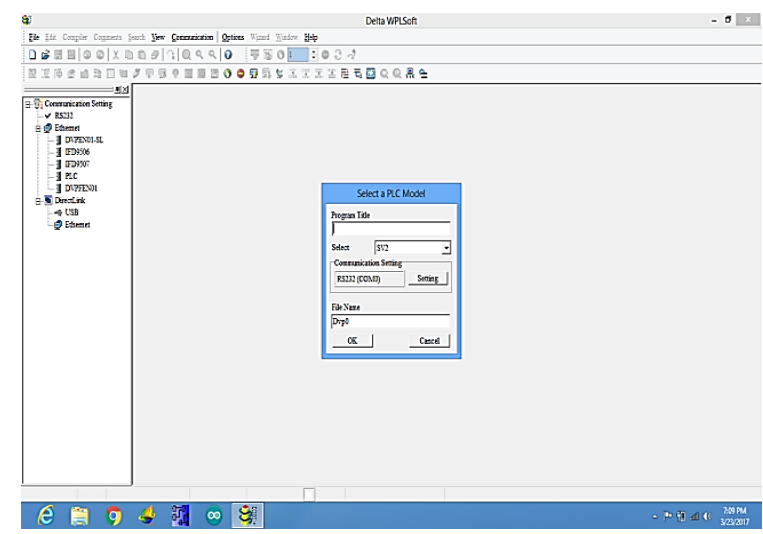

Fig.8: A) NewFile Creation

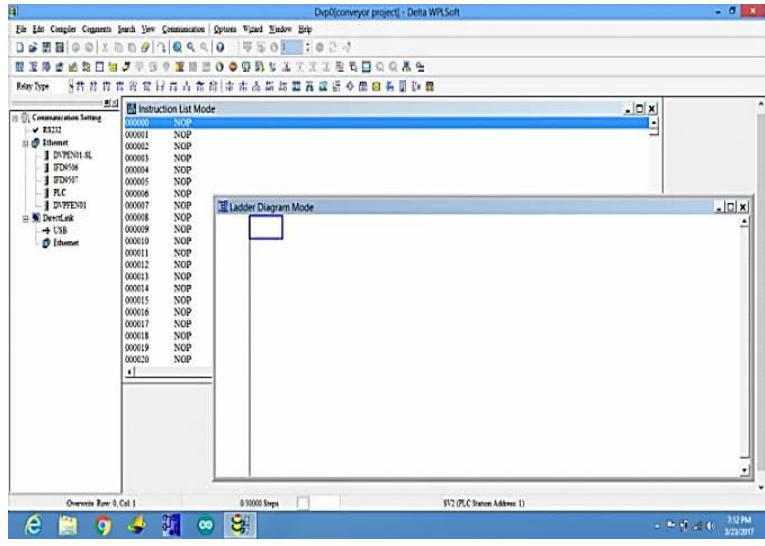

Fig. 8: B) Open Ladder Diagram Mode \& Instruction List Mode

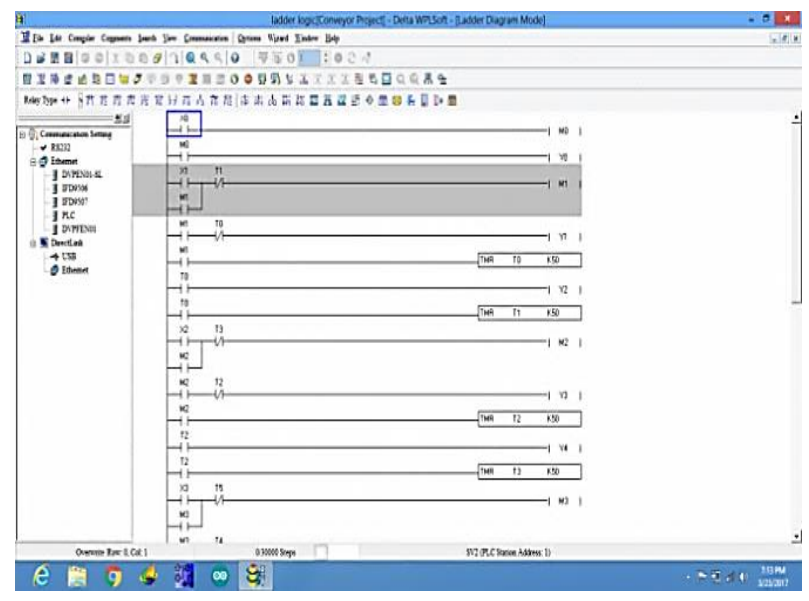

Fig. 8: C)Design Logic Program

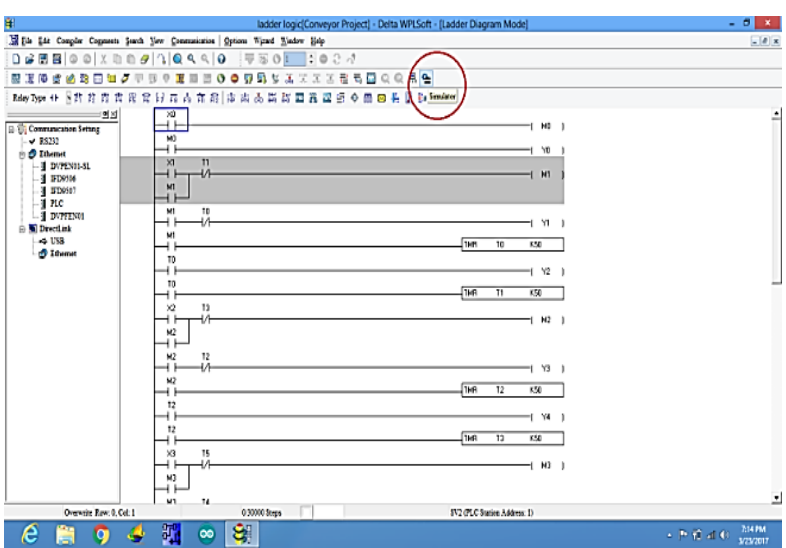

Fig. 8: D) Activate Simulator

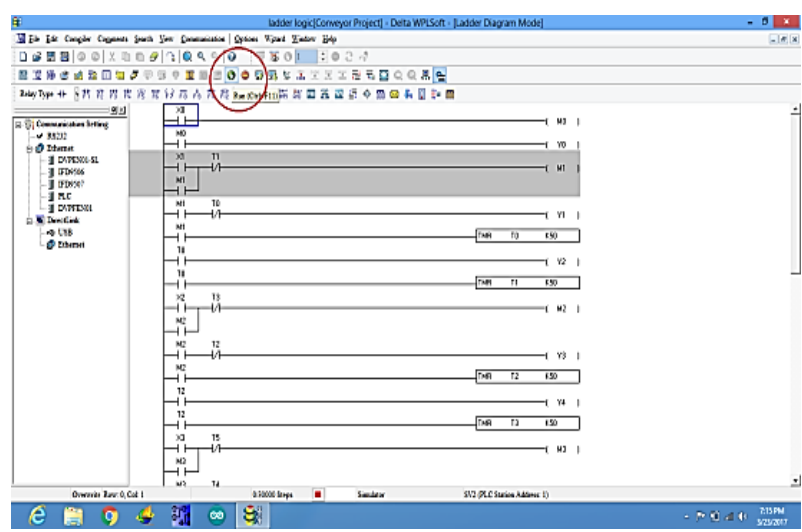

Fig. 8: E) Run Logic Program 


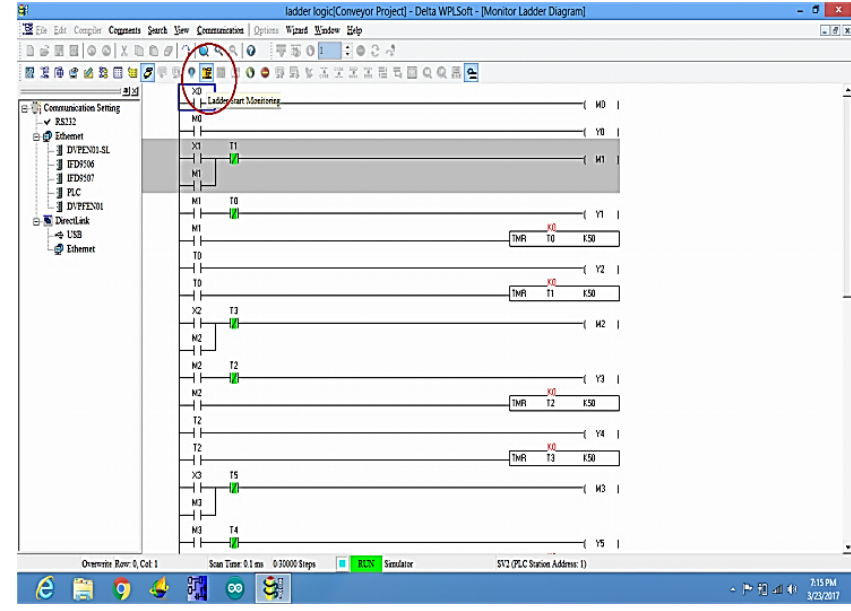

Fig. 8: F) Ladder Start Monitoring

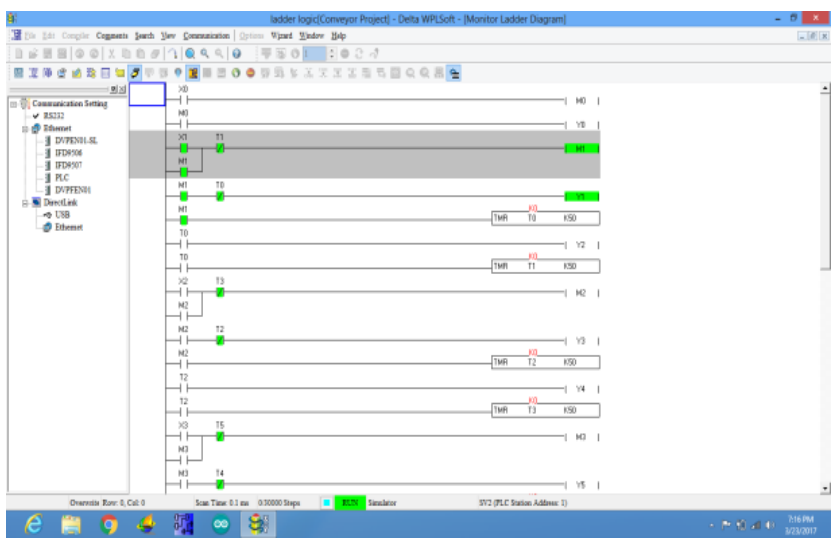

Fig. 8: G) PewterObject Detection

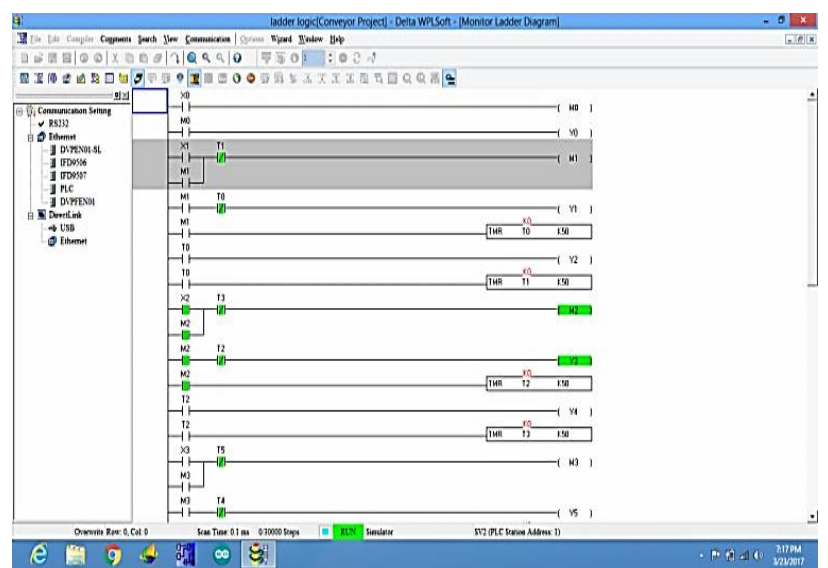

Fig. 8: H) Plastic Object Detection

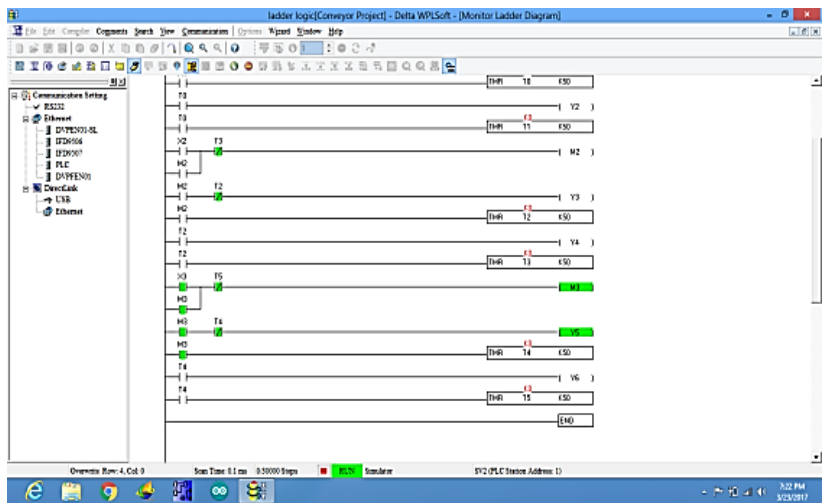

Fig. 8: I) Glass Object Detection

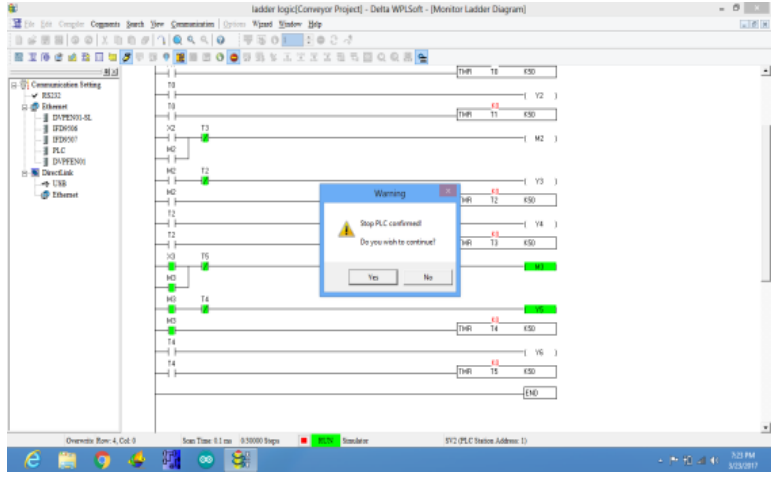

Fig. 8: J) Stop Simulation

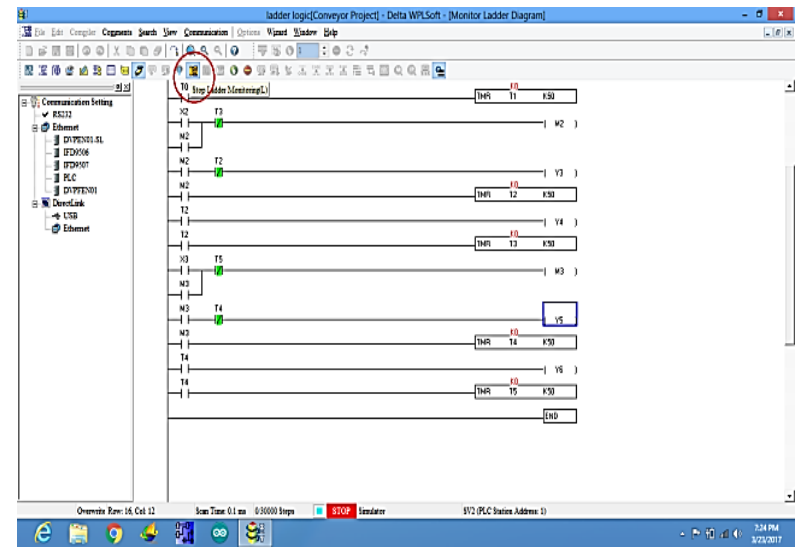

Fig. 8: K) Stop Ladder Monitoring

Figure 8 clearly elucidates the operational of ladder logic by step by step. And the Figure 9 displays the hardware implementation of the automatic material segregation using PLC.

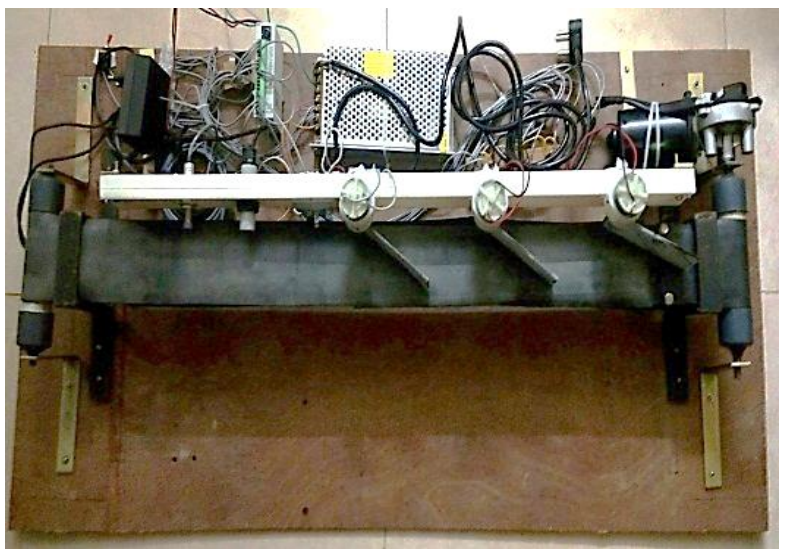

Fig. 9: Hardware Implementation

\section{Conclusion}

In the offeredwork on emerging an affordable and proficient method sort diversesets of plastics bottles, cut-glass bottles and pewter cans hastily and preciselyexhausting PLC. The prearrangementsegregate solitaryuniqueform of material at a phase as the dispensation material object transfers on a conveyor belt unique at a stretchoverdue each other. The entire sensing segment can be traced along a distinctpodium where the object is unwavering to guarantee enhancedconsequence. Automatic material segregation can be principallyrealistic in a number of municipal corporations, enchanting into allegedalteredinfluencesdeclining in manpower, elude risk at precarious places, progressprecision, escalationpromptness of surplus segregation \& etc. 


\section{Future Scope}

1. The routine of PLC offers task associate degree large scope for at hand.

2. By instigating supplementary sensors to comprehend any objects and segregate those reliant on upon the input output module of the PLC

3. A robotic arm will be castoff to relocate associate degree entity in convinced path.

4. Feeder will be recycled to overriding banquet the excess leading into dry and wet leftover.

5. Camera sensors in its place of associate degree log measuring device will be charity where the camera drive spot an object engineered on entity outlined in its compendium.

\section{References}

[1] S.M .Dudhal, B. S. Jonwal, Prof. H. P. Chaudhari, "Waste Segregation Using Programmable Logic Controller", International Journal For Technological Research In Engineering Volume 1, Issue 8, April-2014

[2] Manjunatha "Postal Automation System for Mail Sorting" International Journal of Emerging Technology and Advanced Engineering (ISSN 2250-2459) Volume 5, Issue 3, March 2015)

[3] Y V Aruna, Beena S "Automatic convey or System with In-Process Sorting Mechanism using PLC and HMI System", Int. Journal of Engineering Research and Applications ISSN: 2248-9622, Vol. 5, Issue 11, (Part - 3) November 2015, pp.37-42

[4] JoiceJohny, Abin Joy, Della Sunny, Basil M Joseph \&Shaji M Jamal, "Automatic Plastic Separating Technology For Solid Waste Disposal", International Journal of Civil, Structural, Environmental and Infrastructure Engineering Research and Development (IJCSEIERD)ISSN 2249-6866Vol. 3, Issue 2, Jun 2013

[5] Nidhi Mishra, Rakhi T. Waghmare, Rani B. Phulpagar, Pooja A. Londhe , "Plc Based Scrap Management System",Rani B. Phulpagar et al Int. Journal of Engineering Research and Applications ISSN : 2248-9622, Vol. 4, Issue 3( Version 1), March 2014, pp.26-2.

[6] D. A. Wahab, A. Hussain, E. Scavino, M.M. Mustafa and H. Basri "Development of a Prototype Automated Sorting System for Plastic Recycling" American Journal of Applied Sciences 3 (7): 1924 1928, 2006 ISSN 1546-9239 (C) 2006 Science Publications

[7] M.K.Pushpa, Aayushi Gupta, Shariq Mohammed Shaikh, StutiJha, Suchitra V, "Microcontroller Based Automatic Waste Segregator",International Journal Of Innovative Research In Electrical, Electronics, Instrumentation And Control Engineering vol. 3, Issue 5, May 2015. 